\title{
La traducción como acto doble de comunicación. Entre semiótica cognoscitiva y semiótica de la cultura. ${ }^{1}$ Parte I: De la comunicación a la traducción
}

\author{
Translation as a Double Act of Communication \\ Between Semiotic Cognitive and Semiotics of Culture. \\ Part I: From Communication to Translation
}

\author{
GÖRAN SONESSON \\ Centro de Semiótica Cognoscitiva \\ Universidad de Lund
}

\begin{abstract}
RESUMEN: Si la traducción es un acto de transacción de sentidos, la semiótica debe ser capaz de definir su especificidad en relación con otros actos semióticos. En lugar de eso, siguiendo las sugerencias de Roman Jakobson, de la Escuela de Tartu y, de forma implícita, de Charles Sanders Peirce, la noción de traducción ha sido generalizada para cubrir más o menos todas las operaciones que se pueden llevar a cabo dentro de un recurso semiótico y entre varios recursos semióticos. En este trabajo partimos de una definición de la comunicación elaborada por el autor en un texto anterior, que nos permite caracterizar la traducción como un doble acto de significación, tomando en cuenta los casos de emisión y recepción de ambos actos involucrados, el primero en el nivel de la cognición, y el segundo en el nivel de la comunicación. Sin embargo, el acto de traducción siempre ocurre en un contexto especifico, y, por lo tanto, hace falta ubicarlo dentro del modelo de la semiótica de cultura. En la segunda parte de este artículo, vamos a estudiar las diferencias entre la traducción propiamente dicha, como lo dice Jakobson, y los dos otros tipos de traducción que Jakobson reconoce.
\end{abstract}

ABSTRACT: If translation is an act of meaning transaction, semiotics must be able to define its specificity in relation to other semiotic acts. Instead, following the suggestions of Roman Jakobson, of the Tartu school and, implicitly, of Charles Sanders Peirce, the notion of translation has been generalized to cover, more or less, all the operations that can be carried out within a single semiotic resource as well as between several semiotic resources. In this paper we start with a definition of communication elaborated by the author in a previous text, which allows us to characterize translation as a double act of significance, taking into account the instances of emission and reception of both acts involved, the first at the level of cognition, and the second at level of communication. However, the act of translation always occurs in a specific context, and, therefore, it is

1 La primera versión de este texto se presentó en el congreso de la IASS-AIS en Nanjing en 2012 (véase Sonesson 2014a). Desde entonces, he tenido la oportunidad de ofrecer esta conferencia en Salónica, Helsinki, Lublin, Lund y en la Cuidad de México, y estas experiencias han inspirado cambios fundamentales al modelo propuesto en Nanjing. Quiero agradecer a los que asistieron a estas conferencias; sus comentarios han dado lugar a varias revisiones y aclaraciones. 
necessary to place it within the model elaborated within the semiotics of culture. In the second part of this article, we will study the differences between "translation proper", as Jakobson calls it, and the two other types of translation that Jakobson recognizes.

PALABRAS CLAVE: traducción, comunicación, cognición, semiótica cultural, recursos semióticos

KEYWORDS: translation, communication, cognition, cultural semiotics, semiotic resources RECIBIDO: 5 de febrero de 2018 • ACEPTADO: 29 de marzo de 2018 


\section{GÖRAN SONESSON}

Centro de Semiótica Cognoscitiva

Universidad de Lund

\section{La traducción como acto doble de comunicación. Entre semiótica cognoscitiva y semiótica de la cultura. Parte I: De la comunicación a la traducción}

La traducción es un acto semiótico, y más precisamente, un doble acto de comunicación, que implica al mismo tiempo (como todos los actos semióticos) uno o más actos cognoscitivos, a menudo no solo en el sentido general de la ciencia cognoscitiva contemporánea, sino más específicamente, en el sentido de la psicología cognoscitiva clásica: una operación mental que ocurre en un nivel relativamente alto de conciencia y voluntad. Dado que no todos los actos cognoscitivos, incluso en el sentido amplio del término, son actos de comunicación, la traducción resulta un tema de especial relevancia para la semiótica cognoscitiva, en el sentido en que esta disciplina reúne el estudio de estructuras, como en la semiótica clásica, y el estudio de los actos mentales, como en la psicología y las ciencias cognoscitivas (Daddesio 1994; Sonesson 2007b). Sin embargo, la traducción no es solo un acto doble, sino, es un acto cuyas dos o más partes están, al menos indirectamente, situadas en diferentes ámbitos culturales, mediadas por un sujeto que es el receptor de uno de los actos de comunicación e iniciador del otro. Por lo tanto, es de gran importancia para la semiótica de la cultura.

La teoría tradicional de la traducción, en su conjunto, ha dado el concepto de traducción por sentado, que es tal vez como debe ser - lo que no quiere decir que esta especialidad no ha profundizado en otras cues- 
tiones teóricas, sin importar si se cuentan sus inicios desde Cicerón, Jerónimo, Schleiermacher o Holmes - . En la semiótica, por otra parte, donde se debía haber analizado en sus caracteres específicos el acto de la creación de sentido llamado traducción, existe en lugar de esto una tendencia pronunciada a borrar la distinción entre la traducción y la semiosis en general (Gorlée 1994; Petrilli 2003; Torop 2003, y otros). ${ }^{2}$ Históricamente, hay tres precedentes obvios para este hecho. En primer lugar, en un ensayo muy famoso, Roman Jakobson (1959) sugirió que "la traducción propiamente dicha", rebautizada "traducción interlingüística", podría servir de modelo para lo que él llamaba la "traducción intralingüística", la sustitución de un término por otro, dentro del mismo sistema semiótico, y la "traducción intersemiótica", la transferencia de un significado, de un sistema semiótico a otro). Esto deja abierta la cuestión de si hay algo que pasa en la semiosis que no es traducción.

En un nivel más general, el modelo peirceano del signo, que se concibe mejor como un modelo de comunicación, podría naturalmente sugerir que todo significado es una traducción, como consecuencia de la afirmación de Peirce de que cada una de las tres partes de un signo es susceptible de ser expandida en forma de otro signo, así como de la idea más específica de que un interpretante inmediato se puede transformar en un interpretante dinámico, y así sucesivamente hasta el interpretante final, que quizás nunca se alcance (Colapietro 2003; Petrilli 2003). Tal concepción sugiere aún más fuertemente que toda semiosis es traducción. Por último, el modelo de la Escuela de Tartu de la semiótica cultural (Lotman et al. 1975), utiliza el término mecanismo de traducción con referencia a todos los elementos culturales transferidos de una cultura a otra. El problema compartido de estas tres concepciones es que no nos dicen de qué manera la traducción es diferente de otros actos de comunicación. Para poder decir en qué es específica la traducción, vamos a empezar por indagar la naturaleza de la comunicación como un acto de significación.

Sin embargo, Gorlée (2015) presenta un argumento más semejante al presente artículo, usando transducción como término general, donde nosotros vamos a hablar de transposición (en la sección 4). 


\section{La metáfora del tubo y otras quimeras}

Como Michael Tomasello (2008) observa, la comunicación es un tipo de colaboración. A diferencia de otras especies, este autor hace observar que los seres humanos "han nacido y están criados para ayudar" (2009: 1f). Resulta que los simios son capaces de cooperar cuando el beneficio de la cooperación es mutuo. Incluso pueden, bajo ciertas circunstancias, compartir alimentos. Sin embargo, lo que no pueden hacer es compartir información. Esto sugiere que la información, o, como lo voy a llamar, el conjunto de conocimientos que se comunica, tiene algo de especial, pero Tomasello no tiene nada que decirnos sobre esta especificidad. La semiótica, en general, no ha sido de mucha ayuda aquí tampoco. Aunque los trenes y los coches se mueven, el cambio de posición en el espacio no es un requisito de la comunicación, en el sentido de que un significado se comunica de una persona a otra, al contrario de lo que sugiere la teoría matemática de la comunicación, que sigue siendo aceptada en la semiótica, después de haber sido promovida, en particular, por Roman Jakobson (1960) y Umberto Eco (1976). Cuando Michael Reddy (1979) diagnostica la "metáfora del tubo", una hazaña que hoy en día se presenta a menudo como un descubrimiento temprano de un tema sacado de la cornucopia de "metáforas que vivimos" de George Lakoff, en realidad lo hizo para advertirnos en contra de las sugerencias engañosas incorporadas en esta concepción; de hecho, mucho antes de la invención de la teoría de la comunicación, Valentín Vološinov (1929 [1973]) señaló la implicación equivoca de esta comparación. Sin embargo, ni Vološinov ni Reddy realmente propusieron otro modelo en lugar de esta metáfora seductora. ${ }^{3}$

La comunicación, en el sentido de la presentación de signos, tiene que ser diferenciada del sentido en el que implica medios de transporte como coches, trenes y similares, que cambian su posición en el espacio. $\mathrm{Al}$ igual que el hecho de compartir los recursos alimentarios, que se da entre los simios, la comunicación con trenes y coches implica un mo-

Reddy (1979) sugiere que el "paradigma de los constructores de herramientas" podría ser una opción mejor, pero no hay nada en su propuesta que dé a entender de qué manera esta concepción podría cumplir mejor la función de explicación de la comunicación que la metáfora del tubo. 
vimiento de una posición a otra, y, en todo caso, si se comparte algo, desde luego, no es la información. Dos tradiciones de la semiótica pueden, sin embargo, ayudarnos a clarificar las cosas. Partiendo del modelo de Praga, se entiende que, en la comunicación, el receptor es tan activo como el remitente. Y hay enseñanzas que se pueden sacar del modelo de Tartu. Este último se ocupa en realidad de las relaciones entre las culturas, pero estas relaciones pueden ser reformuladas en términos de actos de comunicación. Lo que la Escuela de Tartu dice acerca de las culturas emisoras y receptoras puede ser concebido como dos posiciones diferentes en el acto de la comunicación (Sonesson 1999).

\subsection{Enseñanzas de la Escuela de Praga}

Jan Mukařovský (1970), el personaje principal de la Escuela Semiótica de Praga en los años treinta del siglo xx, partió de la fenomenología de Edmund Husserl - o, más exactamente, de la interpretación de su seguidor Roman Ingarden (1965 [1931]) - con el fin de describir la comunicación, en particular como se manifiesta en una obra de arte. La aportación fundamental de Mukařovský consistió en desarrollar una dimensión social. La idea más importante de la Escuela de Praga en este contexto, es que, en la comunicación - en el sentido de la transmisión de información-, el transporte o la codificación no son necesarios, pero sí lo es la presentación de un artefacto a otra persona, creando, al mismo tiempo, la tarea de dar un sentido al artefacto. Un artefacto es producido por alguien, y tiene que ser transformado por otra persona en una obra de arte pasando por un proceso de concreción. El término concreción se utiliza aquí en el sentido de Ingarden, para referirse al conjunto de "lugares de indeterminación” presentes en una obra (muchos de los cuales se llenan en una interpretación individual de la obra). Se usa más específicamente en el sentido de Mukařovský, que hace hincapié en la contribución activa, pero, al mismo tiempo, regulada, del receptor o de la audiencia de la obra, que, por otra parte, tiene lugar en un contexto social.

Mukařovský, como Ingarden, formuló esta noción de concreción en referencia a la obra de arte, pero esta concepción se puede generalizar a todo tipo de procesos de comunicación en los que se comparte informa- 
ción o, quizá, mejor, en los que la información se crea conjuntamente. En vista de que, según Mukařovský, este es un acto social, el proceso de creación del artefacto, así como el de percibirlo, están determinados por un conjunto de normas, que pueden ser estéticas $-\mathrm{y}$ en las obras de arte son la especie de normas que deben predominar-, pero también pueden ser de tipo social, psicológico, etc. La obra de arte se define, según la Escuela de Praga, como algo que transgrede estas normas. Mukařovský señala, sin embargo, que las normas pueden ser de cualquier tipo, pasando de regularidades simples a las leyes escritas. Podríamos concluir que existe un continuo que va desde la normalidad a la normatividad, sin que, por lo tanto, las divisiones cualitativas deban ser ignoradas.

Conjunto de conocimientos en $\mathrm{el}$ tiempo/espacio $\mathrm{X} / \mathrm{Y}$

Sistemas de signos, esquemas de interpretación, afordancias, abdacciones, normas, etc.

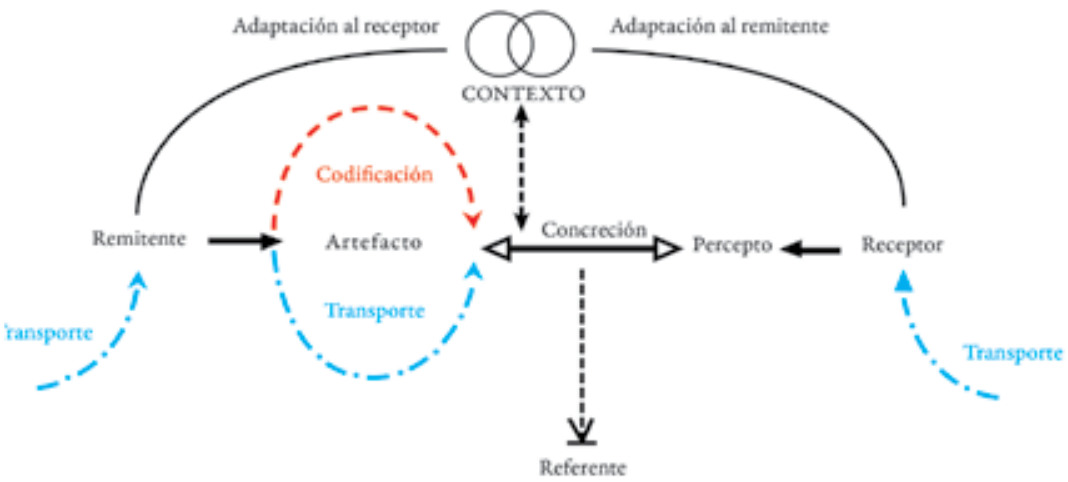

Figura 1. Modelo de comunicación resultando de la integración de los modelos de Praga y de Tartu, según lo propuesto por Sonesson 1999.

Puesto que este modelo se basa en la concepción fenomenológica de la percepción, se puede generalizar fácilmente a la comunicación en general. Todos los tipos de comunicación consisten en presentar un artefacto a otro sujeto, dándole la tarea de transformarlo por medio de una concreción en una percepción. En pocas palabras, lo que sucede en la comunicación, en el sentido relevante, es que un sujeto crea un artefacto, y otro sujeto se enfrenta a la tarea de proporcionar una interpretación a este artefacto (Sonesson 1999). El término concreción se utiliza aquí, en lugar de simplemente percepción, para hacer hincapié 
en el hecho de que la información se produce en una colaboración entre los sujetos. La recodificación a veces es necesaria, pero en la mayoría de los casos, los mismos signos, o al menos los mismos repertorios de signos que coinciden en parte, se pueden usar en ambos extremos de la cadena de comunicación.

Como ya se ha señalado anteriormente, el cambio de posición no es un ingrediente necesario de este proceso, contrariamente a lo que sugiere la teoría matemática de la comunicación. Cuando se envía el mensaje en forma de carta, el tren o el avión tiene que ayudarle en su camino hacia el receptor, y, por esto, se necesita un cambio de lugar. A veces, el remitente tiene que ir a algún lugar en particular para crear el artefacto. El telégrafo, todavía corriente hacia finales del siglo xx, requiere tal desplazamiento. Por el contrario, la comunicación por correo electrónico no requiere más desplazamientos por parte del remitente o receptor que sentarse delante de una computadora o, más recientemente, poniendo en marcha un celular. A veces es el receptor el que tiene que ir a otro lugar para recoger el mensaje. Este sigue siendo el caso cuando se visita un museo, una galería, un cine, un teatro, un salón de automóviles, y así sucesivamente; y se aplica en un sentido más profundo a la experiencia de observar pinturas rupestres prehistóricas originales o frescos renacentistas in situ. En otras palabras, a veces el remitente y/o el receptor tienen que moverse, además de, o en lugar del artefacto (figura 1). El desplazamiento es, por tanto, una cuestión bastante separada de la comunicación. El transporte puede ser la ocasión para la comunicación. De hecho, el movimiento siempre ha ofrecido nuevas perspectivas, incluso a los antecesores del Homo sapiens y otros animales. Precisamente porque el movimiento puede ser un concomitante de tipos específicos de comunicación, el desplazamiento espacial y la comunicación tienen que ser distinguidos desde antes.

Siguiendo el modelo de la Escuela de Praga, toda interpretación también tiene lugar de acuerdo con un conjunto de conocimientos, más o menos compartidos entre el emisor y el receptor, que tienen dos materializaciones principales: el conjunto de obras ejemplares de las artes y el canon, en el sentido de las reglas acerca de cómo las obras de arte deben ser hechas. Una vez más, este doble aspecto de los conocimientos antecedentes puede ser generalizado del caso especial del arte 
a cualquier artefacto que se ofrezca para la comunicación. Por un lado, hay ciertos artefactos ejemplares, y, por el otro, están los esquemas de interpretación.

La noción de esquema tiene una historia en la fenomenología, en particular, en la de Alfred Schütz, así como en la psicología cognoscitiva, desde la obra original sobre la memoria de Frederick Bartlett y de la psicología genética de Jean Piaget, hasta las contribuciones más recientes a la ciencia cognoscitiva, en los trabajos de Rumelhart y Schank. Resumiendo, esta larga y variada tradición describe un esquema como: "una estructura de conjunto dotada de un significado particular - más o menos fácilmente expresable como una etiqueta-, que sirve para agrupar un conjunto de unidades de significación en otros aspectos independientes, y para relacionar los miembros del conjunto el uno con el otro" (Sonesson 1988: 17).

Bartlett habló principalmente de esquemas de memoria, y Schank menciona en particular el esquema del restaurante. Diferentes culturas pueden tener diferentes esquemas de memoria, lo que significa que una historia que viene de una cultura se vuelve a contar, por memoria, de manera diferente, por los miembros de otra cultura, quienes utilizan esquemas imperantes en su cultura. El esquema restaurante es algo mucho más específico; implica un conocimiento sobre la manera de comportarse en un restaurante, que también puede ser, sin duda, diferente de una cultura a otra. Como veremos, artefactos y esquemas resultan ambos relevantes para el acto de la traducción. De hecho, incluso puede haber esquemas que permitan la mediación entre una cultura y otra; así, como ha sugerido Gruzinski (1999), fue el auge del arte grotesco, vigente en Europa con su proliferación de figuras, el que dio a los artistas nativos la oportunidad de integrar a los dioses precolombinos con el cristianismo, incluso en los frescos de las iglesias.

\subsection{Orientación al remitente / fuente - o al receptor / objetivo}

De acuerdo con una idea, sugerida por Lotman (1976), así como por Moles (1981), el emisor y el receptor de cualquier situación de comunicación comienzan con "códigos" - o, como yo prefiero llamarlos, 
recursos de interpretación-, que se superponen solo en parte, esforzándose para homogeneizar el sistema de interpretación a medida que avanza la comunicación. Podemos extender esta idea haciendo referencia a la concepción de la Escuela de Tartu, según la cual las culturas pueden estar orientadas hacia el remitente o hacia el receptor (Lotman et al. 1975), transfiriendo estas propiedades a las situaciones de comunicación. El acto comunicativo puede, entonces, describirse como orientado hacia el remitente o la fuente, en la medida en que se considera como tarea del receptor o de la meta recuperar la parte del sistema de interpretación que no es compartida por los participantes. Está orientado hacia el receptor o el objetivo en la medida en que la tarea de recuperar el conocimiento que los participantes no tengan en común se asigne al remitente o a la fuente (figura 1). En otras palabras, una situación de comunicación está dirigida hacia la fuente cuando es el receptor (objetivo) quien tiene que adaptarse a los recursos interpretativos a disposición de la fuente (remitente); y la situación de la comunicación está dirigida hacia el objetivo cuando es el remitente (fuente) el que tiene que adaptarse a los recursos interpretativos a disposición del receptor (objetivo).

$\mathrm{El}$ arte, tal como es concebido bajo el régimen de la modernidad, ha sido característicamente orientado hacia el remitente; los medios de comunicación, en el sentido arraigado del término (que no es realmente aplicable a todos los medios de comunicación modernos), han sido notablemente orientados al receptor. Un diálogo tiene lugar cuando cada uno de los sujetos adaptan sus esquemas de interpretación a los del otro; es decir, en términos de Piaget, cuando hay tanto acomodación como asimilación. Esto, normalmente supone que haya una gran parte de conocimientos comunes desde el principio. Por otro lado, cuando el remitente y el receptor no pueden negociar las partes del sistema de interpretación que ambos no poseen, la concreción resultante será una deformación. Uno, o ambos sujetos, asimilan entonces el mensaje sin acomodarlo. En este sentido, tanto la orientación al remitente como la orientación al receptor son deformaciones; pero son normalmente deformaciones prescritas por la cultura.

A pesar de que vienen de una tradición diferente, o más bien dos tradiciones bastante diferentes, hay términos familiares para describir estas orientaciones: la adaptación a la fuente, y, más generalmente, toda 
la dimensión que va del receptor al emisor puede denominarse la dimensión hermenéutica: se trata de la forma de entender al otro y/o sus obras. La adaptación al objetivo, y toda la dimensión que va del emisor al receptor, se puede llamar la dimensión retórica, porque se trata de la mejor manera y la más eficaz para hacer llegar el mensaje al receptor. La dimensión global, que se refiere a los recursos que se tienen a mano, es propiamente semiótica.

\subsection{Una nota sobre la comunicación y los signos}

En este y en algunos artículos anteriores (en particular Sonesson 1999), he tratado la semiosis como un acto de comunicación. Muchos de mis lectores, sin embargo, estarán más familiarizados con los textos en que concibo la semiosis en términos de signos, y enumero los criterios para que algo sea un signo (Sonesson 1989; 2007b). Siguiendo la tradición de Humboldt, pasando por Bühler y Coseriu, yo creo que tiene sentido tratar la semiosis a veces como un acto o un proceso, y en otras ocasiones como una estructura, es decir, tanto como Sprechhandling y Sprechakt, y como Sprachwerk y Sprachgebilde, para usar la versión de las distinciones de Bühler (1965 [1934]). Puesto en términos más actuales (y necesariamente con un sentido en parte diferente), la significación puede muy bien ser una representación y una (en)acción al mismo tiempo (Sonesson, en preparación). De hecho, sobre esta base he sostenido que lo que Peirce llama signo se entiende mejor como el acto de comunicación transmitiendo el signo, dejando así el signo en sí totalmente fuera de la ontología peirceana (Sonesson 2013b).

\section{La semiótica de la cultura - entre Alius y Alter}

La semiótica de la cultura fue inventada por Jurij Lotman, Boris Uspenskij y otros estudiosos de la llamada Escuela de Moscú-Tartu en los años sesentas del siglo pasado (Lotman et al. 1975). En la versión original, el modelo se refería a la oposición entre la Cultura y la no-cultura, concebida como una diferencia entre el orden y el desorden, 
así como entre muchos otros términos binarios. ${ }^{4}$ La semiótica de la cultura construye modelos de modelos de culturas - o sea, metamodelos de automodelos - ya que son creados por los miembros de una cultura (o están implícitos en su comportamiento). Estos modelos se refieren esencialmente a las relaciones que existen (de acuerdo con un modelo particular) entre la propia cultura y otras culturas (subculturas, etc.) -es decir, los modelos están egocéntricamente definidos, en el sentido literal de ser definidos desde el punto de vista de alguien que alguna vez se dice "yo" - . Los modelos mutuos de diferentes culturas pueden, al menos en parte, determinar la forma en que estas culturas se comunican entre sí. Una de estas formas de comunicación es lo que usualmente llamamos traducción.

\subsection{Artefactos y esquemas}

El modelo de la Escuela de Tartu trata de las relaciones entre las culturas y, más específicamente, de las comunicaciones que tienen lugar entre diferentes culturas. Como lo ha reconocido más claramente Jennie Mazur (2012), esto significa que la semiótica de la cultura es un modelo de (las dificultades de) comunicación (figura 2). De acuerdo con el modelo original de la Escuela de Tartu, cada cultura posee "mecanismos de traducción", permitiendo que algunos "textos" (es decir, artefactos) puedan ser importados a la propia cultura, a menudo en un estado deformado, mientras que otros son totalmente rechazados en el dominio de los "no-textos "(es decir, no son artefactos en la cultura en cuestión), por medio de un "mecanismo de exclusión" específico. A modo de ejemplo, con la llegada de los españoles a México, los antiguos dioses tuvieron que ser excluidos de la cultura mesoamericana, o tuvieron que ser combinados de una manera u otra con los nuevos dioses y santos promulgados por la nueva religión cristiana. Aquí, el término traducción se utiliza en un sentido muy amplio, que puede muy

Sigo aquí el modelo original, en la manera que después fue elaborado por Sonesson $(2000 ; 2004 ; 2007 a ; 2012 ; 2013 a)$. La noción de 'semioesfera' fue utilizada más tarde, en parte, para el mismo propósito que la noción de 'cultura', pero también se usó en sentidos bastante diferentes, lo que dejó la noción bastante difusa. 
bien ir más allá de la generalización de Jakobson, pero tal vez no de la de Peirce (en el sentido mencionado en la introducción a este artículo; véase también la sección 3.3).

De hecho, traducción cultural parecería implicar la sustitución de los hábitos de una cultura por los de otra, y esta sustitución no incluye necesariamente el uso de una lengua en lugar de otra, sino, más en general, la adopción de otras pautas de comportamiento. ${ }^{5}$ Así, por ejemplo, sin siquiera cambiar el idioma, sustituyendo los patrones correctos de comportamiento mexicano por los patrones españoles, eso podría significar establecer una equivalencia al nivel de la corrección en cuanto a la totalidad de la cultura, es decir, una traducción, en el sentido de la semiótica de la cultura, haciendo uso de secuencias de acción que son al mismo tiempo muy diferentes, incluso, opuestas, en su significado directo. El esquema de restaurante puede que no sea muy diferente en general, pero hay grandes diferencias con otros esquemas en los que este a menudo es integrado, o que están incrustados en él. Uno puede encontrar algunos ejemplos de ello en la obra de Octavio Paz (1986), quien, cuando se dispone a describir lo que es propio de un mexicano, parece implícitamente contrastarlo con el ser español. ${ }^{6}$

En lo que sigue voy a desistir del uso de las nociones de la Escuela de Tartu como 'texto' y 'no-texto', ya que estos términos sugieren analogías con construcciones lingüísticas engañosas, excepto en el caso en que el lenguaje está muy involucrado. En su lugar, vamos a hablar de artefactos y no-artefactos (de hecho, sobre Ego-artefactos, Alter-artefactos y Alius-artefactos, como se explicará más adelante), y, a los artefactos ordinarios, vamos a añadirles los artefactos ejemplares y los esquemas de interpretación.

Queda abierta la cuestión de si todos estos cambios de comportamiento pueden ser entendidos como instancias de traducción intersemiótica, en el sentido de Jakobson. Otro escritor mexicano, Carlos Fuentes (1992), sugiere que los latinoamericanos y los españoles albergan un patrimonio común de estoicismo, derivado del filósofo iberorromano Séneca, pero al menos desde el punto de vista de un observador externo, el estoicismo, en cualquiera de los sentidos del término, no parece particularmente preponderante en ninguna de estas culturas. 


\subsection{Ego y Alter}

La noción del mundo de la vida (Lebenswelt) propuesta por Edmund Husserl, en tanto que "el mundo dado por sentado", se ha convertido ya en un término tan familiar, que muchas personas lo utilizan sin saber quién concibió primero esta idea. En su obra posterior, sin embargo, Husserl distingue entre el mundo familiar (Heimwelt) y el mundo ajeno (Fremdwelt), según lo descrito por Steinbock, y esta distinción se puede entender como una especificación del Lebenswelt, es decir, del mundo en que vivimos, del mundo que se da por sentado, y del mundo que pensamos que otra gente da por sentado. En este sentido, el mundo familiar no es "one place among others, but a normatively special geo-historical place which is constituted with a certain asymmetrical privilege" 7 (Steinbock 1993), y que se puede identificar con una familia o con toda una cultura. En cada caso, lo que está fuera del mundo familiar es el mundo ajeno. Esto parece ser la misma concepción, claramente sin que haya ninguna influencia, que la formulada por la Escuela de Tartu. En ese modelo, la cultura se opone a la naturaleza o la no-cultura, como el interior a lo de afuera, el orden al desorden, la civilización a la barbarie, y así sucesivamente. En otro lugar he llamado esto el modelo canónico, observando que se define desde el punto de vista de la cultura, colocando implícitamente el Ego en su interior, observando a la no-cultura como estando afuera (Sonesson 2000). Al igual que la Escuela de Tartu, Husserl solo hace una distinción binaria aquí, pero, como veremos, puede ser necesario ir más allá del modelo canónico.

Por definición, solo hay un mundo familiar, pero, de acuerdo con lo que he llamado (Sonesson 2000; 2004; 2007) el modelo ampliado (figura 2), en realidad hay dos tipos de mundos ajenos, o dos tipos de otros que los definen. Es decir, hay a quienes uno trata como diferentes, pero iguales, a quienes uno dirige la palabra, y el tipo de otros que son realmente otros egos. Estos representan la segunda persona de la gramática, o, en otras palabras, el Alter. Existen otros a los que uno trata como cosas, como la tercera persona de la gramática, o, en otros términos, como Alius.

\footnotetext{
7 "un lugar entre otros, pero un lugar geohistórico normativamente especial que se constituye con un cierto privilegio asimétrico"
} 


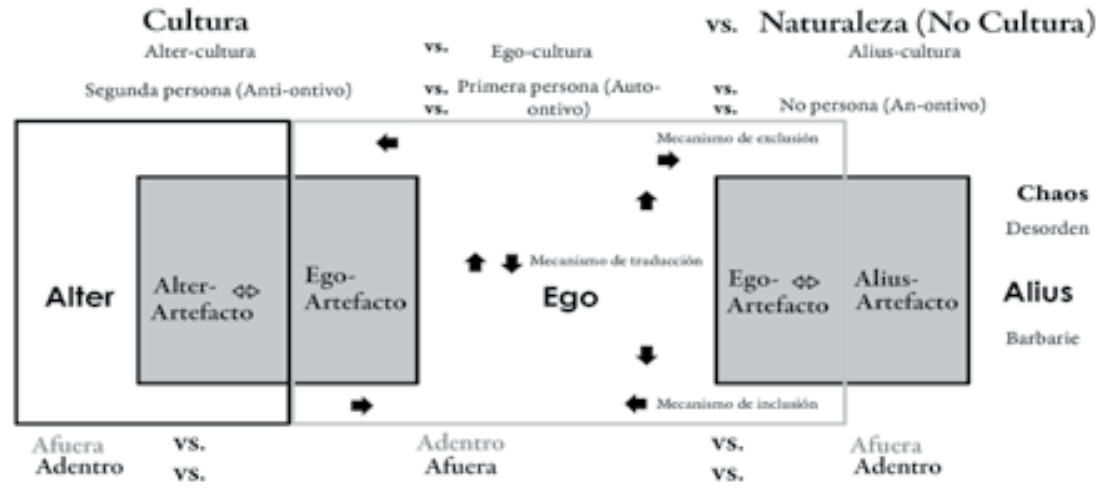

Figura 2. El modelo ampliado de la semiótica de la cultura, como se presenta en Sonesson 2000 , con las mismas modificaciones.

El primero es el tipo de otro que Ego reconoce como siendo otro Ego (en el sentido del "Tuismo" de Peirce), el otro simétrico o, para acuñar un término, el otro peirceano. Constituye el eje de la conversación. El segundo es el otro asimétrico o bajtiniano, que no es un otro que puede ser un Ego. Un caso extremo podría ser el otro sartreano o hegeliano: el esclavo que no logró convertirse en maestro (pero esto supone una fase simétrica anterior, no de diálogo, sino de combate). El segundo otro es el otro de la referencia o de la nominación. Dadas estas definiciones, en lo que sigue vamos a adoptar, a raíz de una sugerencia de Anna Cabak Redei (2007), los términos Ego-cultura, Alter-cultura, y Alius-cultura para describir los tres dominios del modelo ampliado.

\subsection{Alter y Alius}

Emile Benveniste (1966) sugirió en un análisis muy citado que lo que se considera normalmente pronombres de la primera, segunda y tercera personas, realmente debe ser considerado como el resultado de la combinación de dos dimensiones diferentes: la correlación de la personalidad, que opone la persona a la no-persona, y, dentro del polo anterior, la correlación de la subjetividad, que opone el sujeto al no-sujeto. La tercera persona tradicional, en este sentido, no es una persona en abso- 
luto, y se opone a dos clases de personas, de las cuales la primera se identifica con el hablante y la segunda con el oyente. ${ }^{8}$ Lucien Tesnière (1969) propuso más tarde, utilizar los términos — algo más esclarecedores, pero más engorrosos - autoontivo, antiontivo y anontivo: es decir, el que existe en sí mismo, el que existe en contraste (al primero), y el que, hablando con propiedad, no existe en absoluto. Se podría decir, entonces, que la Ego-cultura es el dominio del sujeto, o autoontivo, mientras que la Alter-cultura es el dominio del no-sujeto, o antiontivo; la Alius-cultura, al final, es la residencia de la no-persona, o anontivo. Parece especialmente adecuado, desde el punto de vista de la Ego-cultura, describir la Alius-cultura como aquello que no existe realmente.

Entre los descubridores clásicos del Nuevo Mundo, Colón, que hizo listas de todo tipo de recursos, incluyendo a los seres humanos entre los metales preciosos, los animales y las plantas; es un buen ejemplo de alguien que concibió el continente americano como un Alius: mientras que Cortés, que emplea intérpretes y se aprovecha de los mitos de los aztecas para integrarse a su mundo, adopta la actitud que uno tiene frente a un Alter (Todorov 1982). En el presente contexto, es interesante observar que, mientras Colón llevó consigo un intérprete que entendía el hebreo y el árabe, al parecer esperando encontrar a nativos que hablaran una especie de lengua extranjera genérica, Cortés logró establecer una cadena de traductores: Aguilar, haciendo la interpretación del español al maya, y viceversa, y a Malintzin, haciendo la interpretación del maya al náhuatl, y viceversa (figura 3; Miralles 2004). Así, la distinción es interesante para nosotros, porque el emisor y/o el receptor puede(n) estar situado(s) en una Alter-cultura o en una Alius-cultura. Esta observación sirve, otra vez, para apuntar al hecho de que la semiótica de la cultura trata realmente de los eventos comunicativos. Uno puede ubicarse en el modelo canónico en cierto momento de la comunicación, en el modelo ampliado en otro, y estos diferentes modelos pueden ser distribuidos entre los diferentes participantes en el mismo encuentro. Cabak Redei (2007: 105 ss.) discute la manera opuesta en que la misma reunión entre

En el sentido literal de la gramática se puede referir, por supuesto, a las personas también en tercera persona, pero no es normalmente la manera de invitarlos a participar en el diálogo común (el uso de la tercera persona como una manera respetuosa de dirigirse a una persona puede entenderse de esta manera). 

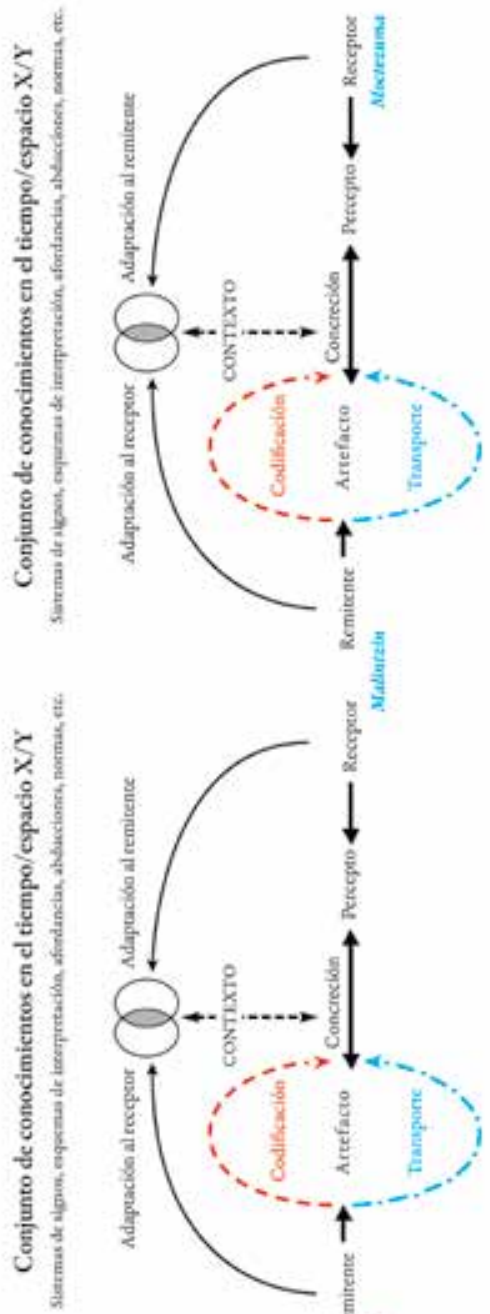

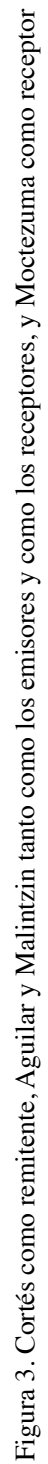
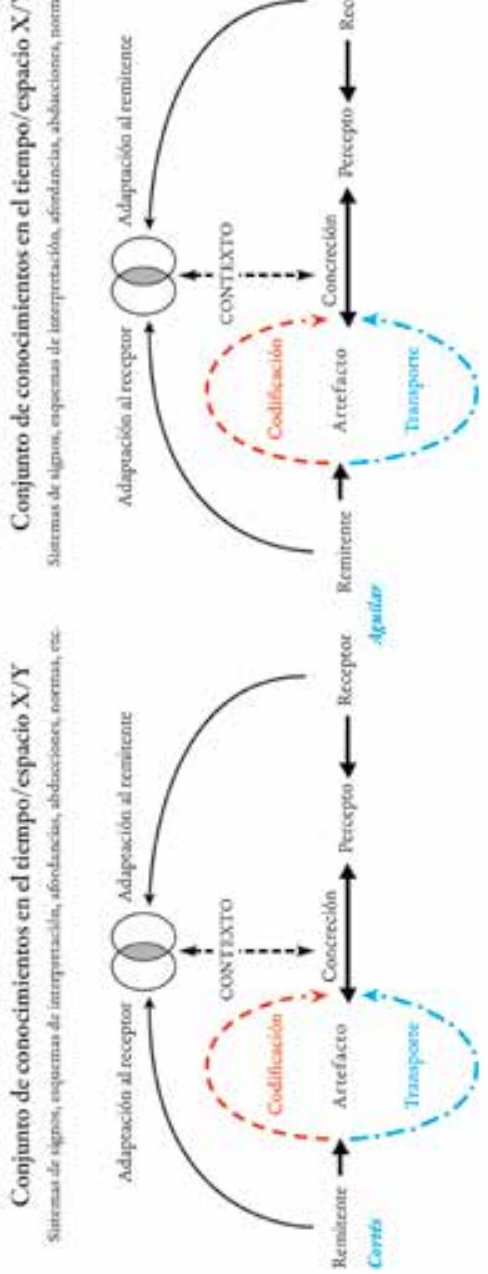
(la francesa) Madame de Staël y (la alemana) Rahel Levin es entendida por las dos personas involucradas, porque cada una de ellas se sitúa dentro de su propia cultura en la misma ocasión. Del mismo modo, Cortés, que en su primer encuentro con los nativos parece haberlos tratado como Alter, más tarde cambia a un trato del tipo Alius frente al mismo grupo, cuando ordena que se destruyan sus "ídolos" (Gruzinski 1990). Por lo tanto, algunos de los acontecimientos relacionados con Cortés y su cultura, por un lado, y los aztecas y su cultura, por el otro, son encuentros del tipo Alius, y algunos son encuentros del tipo Alter.

La semiótica de la cultura trata realmente de eventos comunicativos en los que se enfrentan diferentes culturas. Sin embargo, una serie de este tipo de eventos (tal vez los normales o los normativos) puede abstraerse a un nivel más general, sirviendo para ilustrar la forma en que los encuentros entre estas culturas particulares normalmente tienen lugar. El Cortés que encuentra a los primeros nativos y el Cortés que ordena la destrucción de todos los ídolos en Tenochtitlan no está viviendo el mismo encuentro entre culturas. Se trata de proyectar el modelo de comunicación dentro del modelo de la semiótica de la cultura (figura 4). En este modelo, cualquier pareja de los tres posibles tipos de cultura puede ser puesta en comunicación entre sí, ocupando una u otra de las dos posiciones. Cuando esta comunicación se lleva a cabo utilizando el lenguaje verbal (también escrito o transmitido por gestos), se puede llamar traducción, o, como dice Jakobson "traducción propiamente dicha".

\subsection{El "mecanismo de traducción"}

La discusión anterior nos lleva a la cuestión de si el "mecanismo de la traducción”, tal como fue concebido por la Escuela de Tartu, realmente involucra a la traducción en algo que se acerca al sentido propio (Lotman et al. 1975). Vamos a ignorar por el momento la cuestión de si otros recursos semióticos diferentes al lenguaje pueden ser objetos de traducción, porque vamos a volver a este tema más adelante (en la sección 4). Es importante recordar que nosotros, como habitantes de la Ego-cultura, no estamos en condiciones de hablar con los que viven 
en una Alius-cultura (el único mundo ajeno que existe en el modelo canónico). De hecho, se supone que el mecanismo de la traducción nada más puede importar los "textos" (los artefactos) a condición de deformarlos, si no los manda directamente al mecanismo de exclusión. Por lo tanto, en el México poscolombino, una diosa antigua como Tonantzin, o bien tiene que ser rechazada por completo o, más probablemente, ser disfrazada ("traducida") en la Virgen María. Esto, sostengo, no es ninguna traducción. Cualquiera que sea la parte de verdad que pueda haber en la idea de "traduttore, traditore" (y volveremos a esto más adelante), la meta del acto de traducción sin duda no es esa. El telos o meta del acto de traducción consiste, al contrario, en preservar lo más posible el significado de lo que se traduce. La Escuela de Tartu reconoce que la Ego-cultura puede más tarde establecer su propio mecanismo para engendrar los "textos" (los artefactos) que antes ha importado. No queda claro, sin embargo, si esto equivale a la creación de un mecanismo que simula el mecanismo correspondiente en la otra cultura, o si consiste en la construcción de una manera propia de producir tales "textos" (artefactos).

Conjunto de conocimientos en el tiempo/espacio $\mathrm{X} / \mathrm{Y}$

Sistemas de signos, esquemas de interpretación, afordancias, abducciones, normas, etc.

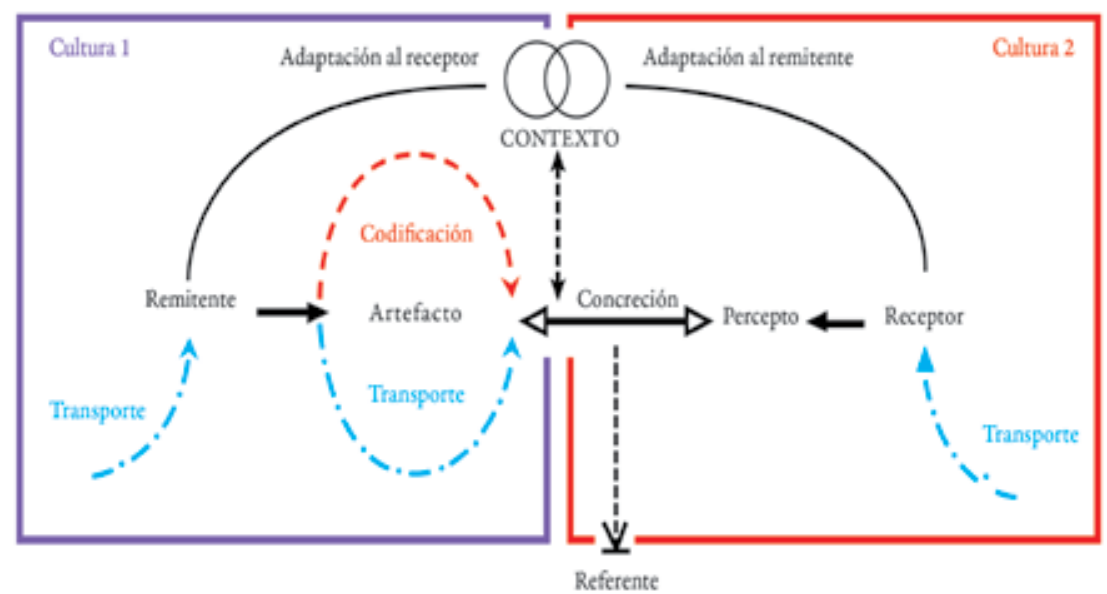

Figura 4. La comunicación entre culturas. La cultura 1 puede ser Ego-cultura, Alter-cultura o Alius-cultura, y la cultura 2 puede ser cualquiera de estas, pero no puede ser del mismo tipo que en la cultura 1. 
Pero ahora hace falta considerar de qué utilidad puede ser un tal mecanismo de traducción en el caso de importar "textos" (artefactos) de la Alter-cultura, o viceversa. Cortés, como dijimos anteriormente, quería ser percibido como siendo Quetzalcóatl, que, sin duda, es un artefacto de la cultura azteca. Más tarde, muchos nativos de Mesoamérica querían que sus representaciones de Tonantzin o Coatlicue fueran percibidas como la representación de la Virgen María (Gruzinski 1999). No se trata en estos casos de un signo intercambiado por otro signo, como en la traducción, ya que, en ese caso, el signo sustituido tiene que ser reconocido como siendo un signo; más bien se parece al camuflaje, que, contrariamente al signo, solo puede funcionar como camuflaje cuando no es reconocido como tal (Sonesson 2010). Esto, al menos, parece describir el tipo de acto cognitivo realizado por Cortés llevando a cabo la identificación de su propia persona con Quetzalcóatl. ${ }^{9}$ No hay ninguna traducción aquí. Pero, en ambos casos, sin duda se trata de crear una equivalencia de un tipo u otro.

En una u otra forma, ambos casos implican el acto cognitivo de la comprensión (y/o la falta de comprensión), que ha sido objeto de mucha discusión en la hermenéutica (Ferraris 1996; lo que no necesariamente quiere decir que se ha aclarado a fondo). ${ }^{10}$ No podemos profundizar aquí en el análisis de este acto fundamental, que no debe ser identificado sin más con la traducción, aunque es una tarea urgente para la semiótica cognitiva.

\section{La semiótica de la traducción}

Un traductor tiene que comunicar en dos direcciones. Pero también el papel del receptor/objetivo es un papel activo, como hemos visto ante-

9 En una etapa posterior, sin duda, la Virgen María fue realmente combinada con Tonantzin en lugar de ser simplemente un camuflaje de ella. Esto correspondería entonces a una etapa en la que la cultura involucrada había establecido un mecanismo adecuado para engendrar artefactos, que originalmente venían, en parte, de una cultura ajena, y en parte de la propia cultura.

10 Como ya he señalado en otra parte (Sonesson 2000; 2004), hay al menos dos criterios diferentes, que no deben confundirse, para que algo sea un "texto" de una cultura: ser interpretable, y ser altamente valorado. La lengua sagrada es un caso obvio en que estos criterios no coinciden. 
riormente. Lo que está pasando es, ciertamente, más complicado que simplemente la sustitución de un elemento de código por un elemento del otro código. El acto de interpretación necesita tener lugar, al menos, dos veces. Y lo mismo ocurre con el acto de crear el mensaje. Y todos estos actos tienen, de alguna manera, que integrarse.

\subsection{La traducción como un doble acto de comunicación}

En el fondo, la idea de que la traducción es un doble acto de comunicación tiene algo de obvio. Estando en un punto extremo de la cadena de receptores, quisiera leer una nueva novela de Mo Yan, pero soy incapaz de leer chino. Por lo tanto, alguien tiene que haber leído la novela antes que yo, y este debe ser una persona que pueda entender chino. También debe ser una persona que pueda escribir en mi idioma. ${ }^{11}$ Esta persona está, entonces, en el punto final de un proceso de comunicación, pero en el inicio de otro proceso. Lo antes dicho sobre la traducción como acto doble de comunicación nos permite ver más claramente cuáles son las condiciones de posibilidad de un acto de traducción que cuando uno se basa en los modelos anteriores. Se trata en particular de las siguientes observaciones: que el receptor es un sujeto activo, que debe concretizar el artefacto producido por el remitente en forma de una percepción; que los dos sujetos interviniendo en un juego de comunicación tienen recursos para la interpretación a su disposición que solo se solapan parcialmente y, por lo tanto, tienen que recuperar los recursos del otro sujeto, o una parte de ellos, para que tenga éxito el acto de comunicación; y que la comunicación puede volverse más difícil porque el emisor y el receptor se encuentran en diferentes culturas, en particular en diferentes Ego-culturas en relación con Alius-culturas y/o Alter-culturas; y esto se aplica a menudo a la situación de los tres participantes en un acto doble de comunicación.

11 Hoy en día, desgraciadamente, también puede ser alguien que no puede escribir mi lenguaje, pero que escribe en inglés, cuya versión será leída por alguien que pueda escribir mi idioma y que traduzca el texto del inglés. Esta es una práctica editorial repugnante que existe en la actualidad. Lo que es peor, podría ser alguien que comprende un solo idioma y que utiliza la traducción de Google o algún dispositivo similar. 
El traductor es un sujeto doblemente activo, como intérprete y como creador de un nuevo texto. Él, o ella, es el receptor de un acto de la comunicación y el remitente, del otro. Primero tiene que transformar el artefacto en un objeto de su propia experiencia. Este es un proceso que no se puede describir como una codificación, en el sentido propio de la palabra, ya que este término sugiere un simple intercambio de un elemento codificado por otro. La correspondencia a menudo tiene que estar en un nivel mucho más alto de comprensión.

Como en cualquier acto de comunicación, los recursos de interpretación a la disposición de (como mínimo) tres actores que intervienen solamente coinciden en parte. Al final, esta falta de coincidencia nunca puede ser completamente subsanada. Sin embargo, determina dos estrategias diferentes del sujeto intermedio, el traductor. Se puede adaptar al emisor del primer acto de comunicación o al receptor del segundo acto de comunicación - o alguna combinación de estas dos estrategias-. Esto significa que debe situarse en un punto dado entre la dimensión hermenéutica y la dimensión retórica de ambos actos de comunicación (figura 5).

El traductor puede ser miembro de la misma Ego-cultura del remitente o de la misma del receptor. Raramente será miembro de ambas. Como siempre, la pertenencia a una Ego-cultura puede ser determinada al menos por dos criterios: lo que uno entiende mejor y lo que uno más valora. Normalmente, el traductor entiende mejor o el lenguaje que está leyendo o el que está escribiendo. También puede identificarse con la cultura del autor, la cual quiere extender a la otra cultura, o puede identificarse con la cultura del lector, que quiere enriquecer con elementos de la otra cultura. Esto, a su vez, puede determinar en parte sus estrategias de adaptación.

Cualquier traducción que es del todo adecuada, como tal, debe tomar en cuenta dos contextos de remisión y dos contextos de recepción, aunque posiblemente en diferentes grados. El primer contexto de remitente es el del hablante/escritor original, y el segundo es el del propio traductor. Del mismo modo, existe el contexto receptor del texto traducido y el contexto receptor del propio traductor. En este sentido, la traducción es un doble acto de comunicación, y no solo dos actos comunicativos siguiéndose uno al otro. 


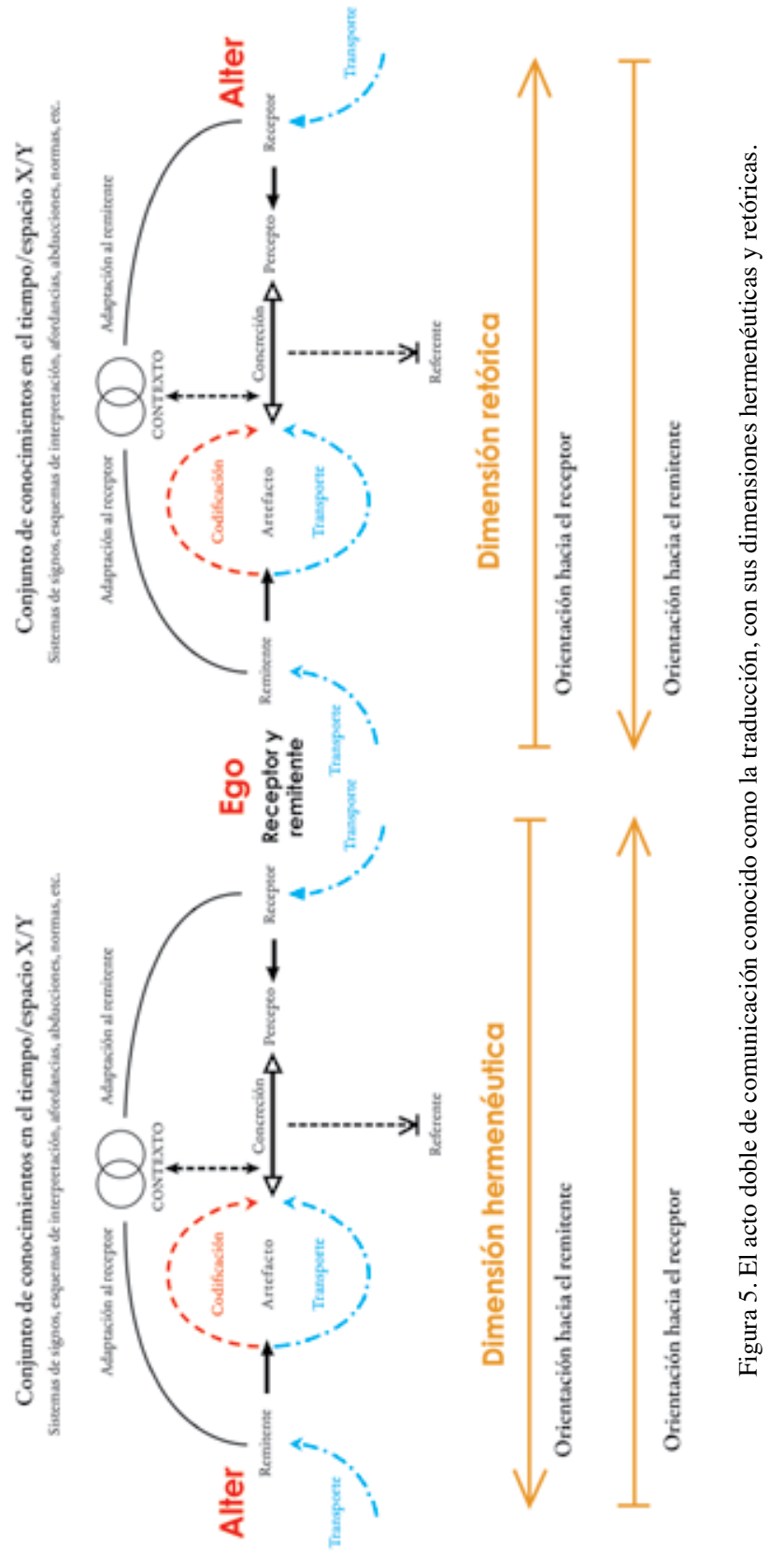




\subsection{Los tipos de traducción de Nida}

Algunos de los que han reflexionado sobre el acto de traducción (que a menudo son los mismos que lo han practicado), especialmente Eugene Nida $(1959 ; 2003)$, ya han estudiado la opción que tiene el traductor de establecer diferentes relaciones con su fuente. De acuerdo con la terminología de Nida, hay una equivalencia dinámica, o equivalencia funcional, cuando el traductor intenta transmitir el pensamiento expresado en el texto de origen (si es necesario, a expensas de la literalidad, el orden de las palabras originales, la voz gramatical del texto de origen, etc.); mientras que hay una equivalencia formal cuando el traductor intenta rendir el texto palabra por palabra (si es necesario, a expensas de la expresión natural en el idioma de destino). Este último, en su caso extremo, es lo que hoy en día conocemos como la traducción de Google, que en realidad no se adapta ni al remitente ni al receptor. Más bien es un caso en que se confunde la traducción con la codificación. La equivalencia dinámica, por otro lado, es una variedad de la adaptación al remitente; más específicamente, a lo que el traductor supone ser su contenido previsto.

Nida, sin embargo, es un traductor con un propósito: se interesa en la traducción de la Biblia. Ni la adaptación al remitente ni la adaptación al receptor parecen justas aquí. La tarea consiste en lograr el mismo efecto en el público contemporáneo o un grupo étnico fuera de la cultura occidental (que ha adoptado el mensaje cristiano como parte de su propio contenido) que la Biblia tuvo en sus primeros lectores. Esto implicaría algún tipo de adaptación al remitente, ya que es el mensaje de los escritores originales el que está destinado a ser transmitido. Pero también requiere algún tipo de adaptación al receptor, pues el efecto que se produjo de una manera, en el momento de la primera remisión, no necesariamente se produce de la misma manera en nuestro tiempo o en otra cultura. Al mismo tiempo, claramente, el traductor aquí se sitúa a sí mismo en la Ego-cultura del productor del texto (de hecho, más bien en la de algunos seguidores posteriores de estos productores, es decir, en este caso, en el de la tradición de interpretación de los bautistas). Esto, sin duda, implica una compleja interacción de adaptaciones al remitente y al receptor. 
En realidad, la traducción de la Biblia cristiana es un acto aún más intrincado de comunicación. La traducción en sí está situada dentro de una larga tradición, cuyas instancias iniciales son, como dice el propio Nida, los primeros lectores de la Biblia en su idioma original. Además, esta tradición se refiere a una gran cantidad de actos de comunicación sucesivos, incluyendo la falta de comunicación entre la Iglesia ortodoxa y la católica, la falta de comunicación que existe entre la Iglesia católica y los protestantes, y, dentro de los rangos de estos últimos, entre los bautistas y los otros protestantes. Estos actos de comunicación cultural o, más exactamente, estos fallos de comunicación culturalmente motivados, no son realmente traducciones propiamente dichas, debido a que su objetivo no es el de transmitir el mismo mensaje, sino de cambiar el mensaje anterior en un mensaje "correcto". La preocupación de Nida con los emisores y receptores, entre los que se ubica, es, por tanto, una búsqueda legítima de teoría de la traducción, pero su interés en producir el mismo efecto en los lectores contemporáneos como en los primeros, es un problema de la teología. Incluso si se refiere a la reacción de los primeros lectores, la comprensión de estos lectores se filtra necesariamente a través de los muchos actos fallidos de comunicación mencionados anteriormente.

\section{Conclusión intermedia: Hacia la transposición}

El propósito fundamental de mi definición de traducción como un doble acto de comunicación es el de restringir la noción de traducción, con el fin de distinguirla de otros tipos de actos lingüísticos y no lingüísticos del significado (Sonesson 2014b, 2017). Es evidente, sin embargo, que esta definición es insuficiente. No hay forma obvia de distinguir un doble acto de comunicación de dos actos consecutivos de comunicación. Así, cuando un rumor sobre algunas consecuencias negativas del uso de ciertos productos se extiende, puede emplearse una agencia de publicidad no solo para negar el rumor en cuestión, sino, también, para transformar la descripción negativa en una positiva, negando así el contenido del primer acto de la comunicación. Pero esto no es un acto de traducción. Para que exista un doble acto de comunicación, y no 
solo dos actos de comunicación siguiendo el uno al otro, el contenido de los dos actos debería ser, en el sentido cualificado del término, idéntico a lo largo de los actos, lo cual, por diferentes razones, es imposible en la transposición intralingüística y la transposición intersemiótica. Por lo tanto, no es la secuencia de un acto de comunicación con otro acto que es una traducción del primer acto a otro idioma lo que hace de la traducción un doble acto de comunicación, sino el hecho de que este segundo acto debe tener en cuenta la situación del emisor y del receptor del acto original, así como del acto que tiene lugar actualmente.

Como lo vamos a ver, la traducción intersemiótica de Jakobson, a diferencia de la traducción intralingüística, conserva algunos aspectos de las propiedades de la traducción propiamente dicha: es, normalmente, un doble acto de comunicación. Sin embargo, los tipos y cantidades de información disponibles para el remitente original, que el "traductor", como receptor y remitente combinado, tiene que recuperar van más allá de las requeridas para el traductor ordinario. Por lo tanto, desde el punto de vista de la orientación hacia el remitente, los requisitos impuestos al primer receptor, para recrear la situación del remitente original, son mucho mayores que en el caso de la traducción propiamente dicha. Esto es lo que vamos a ver en detalle en la segunda parte de este artículo.

\section{Bibliografía}

BÜHLER, Karl (1965 [1934]). Sprachtheorie. Fráncfort, M. Ullstein.

CABAK REDEI, Anna (2007). An inquiry into Cultural Semiotics: Germaine de Staël's autobiographical travel accounts. Tesis. Lund, Lund University Colapietro, Vincent (2003). "Translating Signs Otherwise", en Susan Petrilli (ed.), Translation, Translation. Amsterdam y Nueva York, Rodopi, 189215.

DADDESIO, Thomas (1994). On minds and symbols: the relevance of cognitive science for semiotics. Berlín, Mouton de Gruyter.

Eco, Umberto (1976). A theory of semiotics. Bloomington, Indiana University Press.

FERRARIS, Maurizio (1996). History of hermeneutics. Atlantic Highlands, N.J., Humanities Press

FuENTES, Carlos (1992). El espejo enterrado. México, Fondo de Cultura Económica. 
GORLÉE, Dinda L. (1994). Semiotics and the problem of translation: with special reference to the semiotics of Charles S. Peirce. Amsterdam, Rodopi.

GORLÉE, Dinda L (2015). From translation to transduction: the glassy esssence of intersemiosis. Tartu, University of Tartu Press.

GRUZINSKI, Serge (1990). La guerre des images. De Christophe Colomb à 'Blade Runner'. París: Fayard.

GRUZINSKI, Serge (1999). La pensée métisse, París, Fayard.

INGARDEN, Roman (1965 [1931]). Das literarische Kunstwerk. Eine Untersuchung aus dem Grenzgebiet der Ontologie, Logik und Literaturwissenschaft. Halle, Max Niemeyer. 3. Auflage.

JAKOBSON, Roman (1959). “On Linguistic Aspects of Translation”, en Reuben Brower (ed.), On Translation. Cambridge, Massachussetts, Harvard University Press: 232-239.

JAKOBSON, Roman (1960). "Linguistics and poetics", en Thomas Sebeok (ed.), Style in language. Cambridge, Massachussetts, Massachussets Institute of Technology Press: 350-377.

Lotman, Jurij M., Boris A. Uspenskij, Vjačeslav Vsevolodovič Ivanov, V. N. Toporov y A. M. Pjatigorskij (1975). Thesis on the semiotic study of culture. Lisse, Peter de Ridder.

Lotman, Jurij M (1976). "Culture and information”, Dispositio. Revista hispánica de semiótica literaria, vol. 3, núm. 1: 213-215.

MAZUR, Jennie (2012). Die Schwedische Lösung. Eine kultursemiotisch orientierte Untersuchung der audiovisuellen Werbetexte von IKEA in Deutschland. (1996-2006). Tesis. Uppsala, Uppsala University.

Miralles, Juan (2004). La Malinche. México. Fábula Tusquets Editores.

Moles, Abraham (1981). L'image, communication fonctionnelle. París, Casterman.

MuKǍ̌ovSKÝ, Jan (1974). Studien zur strukturalistischen Ästhetik und Poetik. Munich, Hanser.

NiDA, Eugene A. (1959). "Principles of Translation as Exemplified by Bible Translating", en Reuben Brower (ed.), On Translation. Cambridge, Massachussetts, Harvard University Press: 11-31.

NidA, Eugene A. (2003). "Language and Culture: Two Similar Symbolic Systems", en Susan Petrilli (ed.), Translation, Translation. Amsterdam y Nueva York, Rodopi: 413-424.

PAZ, Octavio (1986). El laberinto de la soledad; Posdata; Vuelta a El laberinto de la soledad. Ed. especial, $1^{\mathrm{a}}$ reimpr. México, Tezontle/Fondo de Cultura Económica.

Petrilli, Susan (2003). "Translation and Semiosis: Introduction”, en Susan Petrilli (ed.), Translation, Translation. Amsterdam y Nueva York, Rodopi: 17-37. 
REDDY, Michael (1979). "The conduit metaphor: A case of frame conflict in our language about language", en A. Ortony (ed.), Metaphor and Thought. Cambridge, Cambridge University Press: 284-310.

SteINBOCK, Anthony J. (1995). Home and beyond: generative phenomenology after Husserl. Evanston, Illinois, Northwestern University Press.

SONESSON, Göran (1988). Methods and models in pictorial semiotics. Report from the Semiotics Project, Lund.

SONEsSON, Göran (1989). Pictorial concepts. Lund, Lund University Press.

SONESSON, Göran (1999). "The signs of life in society - and out if", Sign System Studies, 27: 88-127.

SONESSON, Göran (2000). "Ego meets Alter: the meaning of otherness in cultural semiotics", Semiotica, vol. 128, núm. 3-4: 537-559.

SONESSON, Göran (2004). "The globalisation of Ego and Alter. An essay in cultural semiotics", Semiotica, vol. 148, núm. 1-4: 153-173.

SONESSON, Göran (2007a). "A semiosfera e o domínio da alteridade”, en Irene Machado (ed.), Semiótica da cultura e semiosfera. São Paulo, Annablume: 81-95.

SONESSON, Göran (2007b). "From the meaning of embodiment to the embodiment of meaning", en Tom Zimke, Jordan Zlatev y Roslyn Frank (eds.). Body, Language and Mind. Vol 1. Embodiment. Berlín, Mouton: 85-128.

SONESSON, Göran (2010). "From mimicry to mime by way of mimesis: Reflections on a general theory of iconicity", Sign Systems Studies, vol. 38, núm. 1/4: 18-66.

SONESSON, Göran (2012). "Between homeworld and alienworld: A primer of cultural semiotics", en Ernest W.B. Hess-Lüttich (ed.), Sign Culture Zeichen. Kultur Festschrift for Roland Posner. Würzburgo, Königshausen \& Neumann: 315-328.

SONESSON, Göran (2013a). "Divagations on alterity", en Susan Petrilli (ed.), Writing, voice, text: Festschrift for Augusto Ponzio. Nueva York, Legas: 137-142.

SONESSON, Göran (2013b). "The Natural History of Branching: Approaches to the Phenomenology of Firstness, Secondness, and Thirdness", Signs and Society, vol. 1, núm. 2: 297-326.

SONESSON, Göran (2014a). "Translation as a double act of communication. A perspective from the semiotics of culture", en Yongxianng Wang y Haihong Ji (eds.), Our World: a Kaleidoscopic Network. Proceedings of the 11th World Congress of Semiotics of IASS in Nanjing, October 5 - 9, 2012. Vol. 3: 83-102.

SONESSON, Göran (2014b). "Translation and Other Acts of Meaning: In Between Cognitive Semiotics and Semiotics of Culture", en Cognitive Semiotics, vol. 7, núm. 2: 249-280.

SONESSON, Göran (2017). "The rhetorical act in-between translation and 
seduction", en Evripides Zantides (ed.), Semiotics of Visual Communication II: Culture of Seduction. Actes of the 2nd International Conference \& Exhibition on Semiotics and Visual Communication, Lemesos, Cyprus, October 2-4, 2015. Newcastle upon Tyne, Cambridge Scholars Publishing: 32-53.

SONESSON, Göran (en preparación). "Bodies without Souls and Behaviour without Meanings: A Critique of Radical Enactionism".

TESNIÈRE, Lucien (1969). Éléments de syntaxe structurale. París, Klincksieck. Todorov, Tzvetan (1982). La conquête de l'Amérique. La question de l'autre. París, Seuil.

Tomasello, Michael (2008). Origins of human communication. Cambridge, Massachussetts, Massachussetts Institute of Technology Press.

TomASello, Michael (2009). Why we cooperate. Cambridge, Massachussetts, Massachussetts Institute of Technology Press.

TOROP, Peeter (2003). "Semiótica de traducción, traducción de la Semiótica", Entretextos: Revista Electrónica Semestral de Estudios Semióticos de la Cultura, núm. 1. Disponible en: <http://www.ugr.es/ mcaceres/entretextos/ pdf/entre1/torop1.pdf>, consultado el 20 de agosto de 2014.

VološInov, Valentin N. (1973 [1929]). Marxism and the philosophy of language. Nueva York, Seminar Press. 